\title{
EXPLORING OLDER ADULTS HEARING AND VISION AND DRIVING - THE SWEDISH STUDY
}

\author{
Birgitta Thorslund \\ VTI \\ Olaus Magnus väg 35, Linköping, Sweden \\ Phone: + 46709430440 E-mail: birgitta.thorslund@vti.se
}

Co-authors; Sara Nygårdhs, VTI; Alicja Malicka, La Trobe University; Alexander Black, QUT; Louise Hickson, UQ; Joanne Wood, QUT.

\section{ABSTRACT}

Aim: The aims of this study were to evaluate self-reported driving abilities and self-reported use of visual and hearing aids for driving, among older adults with varying degrees of Hearing Impairment (HI), Vision Impairment (VIA measure of visual processing related to driving performance was also assessed. The following research questions were examined: How are self-reported and clinically measured declines in sensory and cognitive skills associated with: Each other, Level of comfort in various driving situations, and Use of hearing and vision aids when driving.

Method: Participants included 109 older adults (58 women, 51 men) aged over 60 years (Mage $=69.5$ years ( $\mathrm{SD}=5.25)$, age range: $60-87$ ) holding a valid driver's license. Tests of vision, hearing and visual processing were performed to collect objective data. All participants filled in a questionnaire covering subjective measures of vision, hearing, driving habits, and use of vision and hearing aids. Correlations were made to examine the relations between objective and subjective measures.

Results and conclusion: The correlation between subjective and objective measures of both hearing and vision, indicates that participants in this study were aware of their abilities. A better hearing and vision (as clinically measured), were associated with a higher level of comfort in several traffic situations. The results also show that spectacles are used more than hearing aids when driving, in this study $95 \%$ versus $57 \%$ of the time. Both the joy of driving and the perceived driving quality was significantly correlated to hearing and vision, such that better ability led to greater pleasure in driving and higher ratings of driving quality. 


\section{INTRODUCTION}

The ability to drive a car is associated with better health and well-being in older adults (Ellaway, Macintyre, Hiscock, \& Kearns, 2003). However, aging is associated with deterioration of several abilities that are essential for driving including impaired perceptual abilities, such as hearing and vision, memory declines, reduction in the ability to sustain and switch attention, and reductions in mobility (Groeger, 2000). However, aging is usually a gradual process and while some skills deteriorate with increasing age, other more strategic skills may be used to a greater extent with increasing age (Haustein et al., 2013).

Vision function measures (e.g.: visual acuity, visual fields) may be used to predict if a driver is likely to drive a vehicle in a safe manner or not (Thorslund \& Strand, 2016). Compensatory strategies when driving, such as decreased driving speed and more frequent glances in the rear-view mirror, have been associated with hearing loss among older adults (Thorslund, 2014). Cognitive impairments associated with normal aging are also important to consider, since driving is one of the most complex and safetycritical tasks today (Groeger, 2000). Since age-related impairments develop gradually, older adults may not be aware of the severity of their decline or may not perceive that their driving skills have deteriorated.

In Sweden, binocular visual acuity required to hold a driver license clearance B (private car) needs to be at least 0.5 decimal with the best optical correction (Transportstyrelsen, 2012). In most European countries, vision requirements for drivers are introduced between the ages of 45-70 years dependent on the country and are administered at interval between 1-5 years (Bohensky, 2008). Sweden is one of six countries in the EU who do not require medical testing at driving license renewal. In neighboring countries Norway and Denmark, a certificate from medical testing is required from 75 years of age, and in Finland an eye examination is compulsory from 45 years of age. Current debate in Sweden driven by the Swedish Transport Agency is whether a periodical medical test should be implemented for adults aged 65 or 70 years old to check their fitness to drive.

Traditional vision tests, such as contrast sensitivity and visual acuity, are increasingly being combined with tests of visual processing to predict driving performance. An example of such a test is the Useful Field of View (UFOV) which has been suggested to be a reliable indicator/predictor of safe driving/driving performance (Cushman, 1996; Hoffman, 2015; Johnson, 2010; Myers, 2000). Importantly, poor UFOV performance has been linked to elevated crash risk among older drivers (Owsley et al., 1998; Reitan, 1986). Another cognitive test, strongly associated with driving ability in relation to avoiding difficult traffic situations, is the Trail Making Test (Rapoport et al., 2013; Reger et al., 2004).

Some older people use hearing or vision aids to compensate for their respective sensory deficits, however, there is no data regarding the use of hearing and/or vision aid use while driving. In order to be able to guide older adults with sensory impairments regarding whether they should continue driving or not, it is necessary to understand more about how they perceive their own abilities and to what extent they use the aids they have been prescribed. A collaborative project between the Swedish National Road and Transport Research Institute (VTI), Queensland University of Technology (QUT) and The University of Queensland (UQ) in Australia was initiated to examine this topic in both countries. This paper presents the results from data collection in Sweden. 


\section{AIMS AND RESEARCH QUESTIONS}

The aims of this study were to evaluate self-reported driving abilities and self-reported use of visual and hearing aids for driving, among older adults with varying degrees of Hearing Impairment (HI), Vision Impairment (VIA measure of visual processing related to driving performance was also assessed. The following research questions were examined:

How are self-reported and clinically measured declines in sensory and cognitive skills associated with:

- Each other

- Level of comfort in various driving situations

- Use of hearing and vision aids when driving

\section{METHODS}

All data collection was performed in Stockholm at St Erik Eye Hospital by trained optometrists, who were also specifically trained to perform the hearing and visual processing tests. The study was approved by the ethics committee in Linköping (EPN 2015/120-31).

\subsection{Participants}

Participants were recruited by posting invitations to social media and to hearing loss associations. Information about age and annual mileage was collected by means of a questionnaire. Participants included 109 older adults (58 women, 51 men) aged over 60 years (Mage $=69.5$ years $(\mathrm{SD}=5.25)$, age range: $60-87$ ) holding a valid driver's license and residing in Stockholm county, Sweden. The mean annual mileage in kilometers was 7617 (SD =13985). The participants were categorized into four groups according to their hearing and vision abilities as follows: No visual or hearing impairment (NI), visual impairment (VI), hearing impairment (HI), and visual and hearing impairment (VHI). Gender distribution, mean age and age range for each group are shown in Table 1. During the assessments participants were asked to wear their optical correction used for driving, as applicable.

\subsection{Vision tests}

High- (100\%) and low-contrast (10\%) visual acuity (VA) were measured binocularly using participants' habitual distance correction that they wear for driving using an EDTRS-chart at a four meters working distance. VA was scored on a letter-by-letter basis as decimal equivalent and uncorrected VA of at least 1.0 was considered to be normal. Visual fields were tested monocularly with a Humphrey Field Analyzer (using the monocular 24-2 SITA-Fast program) and binocularly using the Esterman test (binocular) (Crabb, 2004). [Need to state cut-off for the VI, as well as the HI below]

\subsection{Hearing tests}

Pure Tone Audiometry (PTA) of four frequencies $(0.5,1,2,4 \mathrm{kHz})$ was conducted according to the WHO methodology (Arlinger, 2007). HI was defined by an average (PTA) $>25 \mathrm{~dB}$. The speech in noise (SIN) test was performed with and without hearing aids using lists and methods from Magnusson and colleagues (Magnusson, Karlsson, \& Leijon, 2001). At a signal to noise ratio $(\mathrm{S} / \mathrm{N})=+4 \mathrm{~dB}$ people with normal hearing will recognize approximately $80 \%$ of the words presented. The quota between SIN without and with hearing aids was used to determine the effect of the hearing aids (in percent) and is denoted SINQ in this paper. 


\subsection{Tests of visual processing}

Driving assessments were not within the scope of this study due to practical constraints. Tests of visual processing, shown to be associated with driving performance were conducted, to provide an index of driving performance. Participants completed a computer-based Useful Field of View test (UFOV®, Version 7). The UFOV assesses the speed at which information can be extracted and processed from a visual scene and is highly relevant for driving given the need to extract visual information across the driving environment in a timely manner (Ball, 2003). Participants were seated $50 \mathrm{~cm}$ in front of a computer monitor, wearing their habitual correction, and performed three subtests. Processing speed is a central discrimination test. Divided attention is a simultaneous central and peripheral discrimination task. Selective attention involves a combination of central and peripheral discrimination tasks in the presence of distractors (Visual Awareness Inc, 2004). The UFOV test was used to understand whether there were differences in predicted crash risk (as derived from scores on the UFOV test) and selfreported driving quality among participants in the four groups.

Participants also completed the pen and paper version of the Trail Making Test (TMT), which assesses visual search, processing speed and mental flexibility (Reitan, 1986) and has shown a strong association with driving ability (Rapoport et al., 2013). TMT part A consists of with a series of numbers, which need to be connected in numerical order, and part B are targets comprising both numbers and letters, which need to be connected in a combined numerical and alphabetical order and the result is the time to complete the task.

\subsection{Questionnaire}

A questionnaire based on other validated hearing and vision surveys was used to collect demographic data, information on general health and medications, self-reported vision and hearing difficulties and use of vision and hearing aids and driving habits. The majority of questions included in the study had a Likert type response scale (Likert, 1932). The questionnaire is presented in appendix and included 6 sections covering:

\subsubsection{Date of birth, gender and general health}

General health was rated on a 5-point scale from excellent to poor.

\subsubsection{Self-reported vision ability}

7 questions covering subjective vision with and without glasses or contact lenses were rated on 5-point scales from excellent to very poor. The difficulty in performing different everyday tasks were rated on 4-point scales from no difficulty at all to extreme difficulty. There were also two alternatives for stopped doing this, either because of their eyesight or for other reasons. This part was based on the 25-item Visual Function Questionnaire (VFQ-25)(Mangione et al., 2001).

\subsubsection{Self-reported hearing difficulties}

2 questions covering self-reported hearing ability with and without hearing aids (HA) rated on scales from excellent to very poor. For people who had hearing aids, the scale Satisfaction with amplification in daily life (SADL) was used (Cox \& Alexander, 1999). Ability to hear in 12 different daily situations were marked on scales from not at all to perfectly, with the possibility of marking not applicable. Participants were also asked to rate on a scale how hard they need to concentrate when listening. The questions were based on Speech, Spatial and Qualities of Hearing Scale (SSQ) and Spatial Hearing Questionnaire (SHQ) (Zhang et al., 2015). 


\subsubsection{Driving habits}

The data on: year of driving license, mileage and driving days per week were collected. Driving pleasure (from No, I don't to Yes, a lot) and self- reported quality of driving (from excellent to poor) were rated on scales. The level of comfort in various driving situations were rated on scales from Not at all comfortable to Completely comfortable.

\subsubsection{The use of glasses when driving}

Participants rated their vision as drivers without glasses and with their glasses if they wore them for driving on a five-point scale ranging from excellent to very poor. They were also asked to what extent (\%) they wear glasses during daytime and night time respectively and how often they wear them in specific situations.

\subsubsection{The use of hearing aids when driving}

Similarly, participants rated their hearing, without hearing aids and with hearing aids if they used them when driving on a five-point scale ranging from excellent to very poor. They were also asked to what extent $(\%)$ they wear hearing aids during daytime and night time respectively and how often they wear hearing aids in specific situations (all the time to rarely or none of the time).

\section{ANALYSIS}

Bivariate correlations were used to examine the three research questions covering the association between self-reported and clinically measured abilities with: each other, self-experienced driving performance, and level of comfort in various situations. A Pearson correlation coefficient was computed to assess the relationship between answers to the questionnaire questions and results of the included cognitive tests and to chronological age. Cohen (1988) was used to guide the interpretation of the strength of significant correlations.

One-way ANOVAs were performed to examine differences between groups for the questions about general health, self-experienced driving performance, and joy of driving. All statistical analysis was performed with IBM SPSS Statistics (version 22) and 0.05 was chosen as the significance level.

\section{RESULTS}

Gender and age distribution are displayed together with driving habits in Table 1 as a function of the different groups. Mean values of objective and subjective measures are presented in Table 2. There were no significant group differences.

Table 1: Gender distribution, mean age and driving habits in each participant group.

\begin{tabular}{|l|c|c|c|c|}
\hline \multicolumn{1}{|c|}{ Participants } & NI & VI & HI & VHI \\
\hline Men/Women & $13 / 10$ & $9 / 20$ & $11 / 11$ & $18 / 17$ \\
\hline Age yrs mean (SD) & $68.8(5.3)$ & $68.1(4.3)$ & $71.3(5.6)$ & $69,8(5.4)$ \\
\hline Age range (years) & $60-83$ & $61-77$ & $62-87$ & $60-85$ \\
\hline Annual mileage km mean (SD) & $8600(9819)$ & $7572(7643)$ & $6634(12442)$ & $7627(20344)$ \\
\hline Week mileage km mean (SD) & $142.6(269.7)$ & $115.2(148.4)$ & $85.8(211.1)$ & $70.5(85.2)$ \\
\hline Driving days/week mean (SD) & $3.4(3.1)$ & $2.6(2.2)$ & $3.2(2.5)$ & $3.1(1.8)$ \\
\hline Driving license years mean (SD) & $47.0(8.0)$ & $48.1(6.3)$ & $49.0(7.1)$ & $48.0(9.4)$ \\
\hline
\end{tabular}


Table 2: Average values and SD for vision, hearing, UFOV, TMT and self-reported measures. Hearing aid $=H A, R=$ right, $L=$ left.

\begin{tabular}{|c|c|c|c|c|c|c|}
\hline & Measure & Unit or scale & NI & VI & $\mathrm{HI}$ & VHI \\
\hline & General health & $\begin{aligned} 1= & \text { excellent to } 5 \\
& =\text { very poor }\end{aligned}$ & $1.9(0.85)$ & $1.6(0.72)$ & $1.76(0.75)$ & $2.29(0.71)$ \\
\hline \multirow{6}{*}{ 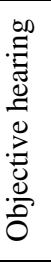 } & PTA No HA right ear (NHA R) & $\mathrm{dB}$ & $19.7(7.5)$ & $20.7(5.5)$ & $39.9(10.3)$ & $41.8(13.4)$ \\
\hline & PTA No HA left ear (NHA L) & $\mathrm{dB}$ & $20.4(5.8)$ & $21.5(5.8)$ & $40.4(13.7)$ & $42.0(11.8)$ \\
\hline & HA right ear (HA R) & $\mathrm{dB}$ & - & - & $32.8(9.7)$ & $35.6(9.9)$ \\
\hline & HA left ear (HA L) & $\mathrm{dB}$ & - & - & $33.7(14.6)$ & $36.0(11.6)$ \\
\hline & $\begin{array}{l}\text { Speech in noise No HA (SIN } \\
\text { NHA) }\end{array}$ & $\%$ & $87.8(6.2)$ & $89.1(7.4)$ & $46.2(14.8)$ & $49.5(16.3)$ \\
\hline & Speech in noise HA (SIN HA) & $\%$ & - & - & $65.1(18.7)$ & $64.4(17.1)$ \\
\hline \multirow{8}{*}{ 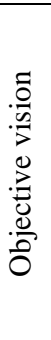 } & High contrast no glasses (HC NG) & decimal & $1.0(0.3)$ & $0.4(0.1)$ & $0.9(0.3)$ & $0.5(0.2)$ \\
\hline & Low contrast no glasses (LC NG) & decimal & $0.6(0.2)$ & $0.3(0.2)$ & $0.6(0.1)$ & $0.3(0.1)$ \\
\hline & High contrast glasses $(\mathrm{HC} \mathrm{G})$ & decimal & - & $1.2(0.3)$ & - & $1.2(0.2)$ \\
\hline & Low contrast glasses (LC G) & decimal & - & $0.7(0.2)$ & - & $0.7(0.2)$ \\
\hline & Visual field (VF) & $\begin{array}{c}\text { Number of dots } \\
\max =120\end{array}$ & $119.9(0.29)$ & $118.9(3.9)$ & $119.5(1.1)$ & $119.3(1.1)$ \\
\hline & UFOV risk category (UFOV) & & $1.5(0.9)$ & $1.3(0.5)$ & $1.6(1.0)$ & $1.4(0.7)$ \\
\hline & Trail making test A (TMTA) & seconds & $47.2(18.8)$ & $40.9(13.1)$ & $56.9(16.4)$ & $43.6(13.0)$ \\
\hline & Trail making test B (TMTB) & seconds & $113.2(42.1)$ & $106.6(43.1)$ & $135.8(43.4)$ & $118.1(42.3)$ \\
\hline \multirow{7}{*}{ 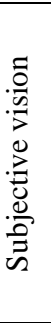 } & Eyesight without glasses & \multirow{2}{*}{$\begin{array}{l}1=\text { excellent to } 5 \\
=\text { very poor }\end{array}$} & $2.4(0.6)$ & $3.3(0.7)$ & $1.9(0.7)$ & $3.0(0.7)$ \\
\hline & Eyesight with glasses & & - & $1.7(0.6)$ & - & $1.7(0.6)$ \\
\hline & Difficulty reading ordinary print & \multirow{5}{*}{$\begin{array}{c}1=\text { no difficulty to } \\
4 \text { = extreme } \\
\text { difficulty }\end{array}$} & $1.5(0.7)$ & $1.2(0.4)$ & $1.1(0.2)$ & $1.4(0.5)$ \\
\hline & Difficulty doing work or hobbies & & $1.5(0.8)$ & $1.4(0.5)$ & $1.1(0.2)$ & $1.5(0.6)$ \\
\hline & $\begin{array}{l}\text { Difficulty finding something on a } \\
\text { shelf }\end{array}$ & & $1.2(0.4)$ & $1.0(0.2)$ & $1.4(0.7)$ & $1.2(0.5)$ \\
\hline & Difficulty reading street signs & & $1.3(0.5)$ & $1.2(0.4)$ & $1.3(1.0)$ & $1.2(0.4)$ \\
\hline & Difficulty going down steps & & $1.4(0.6)$ & $1.6(0.7)$ & $1.6(0.6)$ & $1.6(0.6)$ \\
\hline \multirow{14}{*}{ 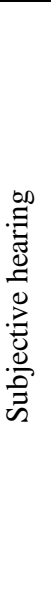 } & Hearing without HA & \multirow{2}{*}{$\begin{aligned} 1= & \text { excellent to } 5 \\
& =\text { very poor }\end{aligned}$} & $1.8(0.7)$ & $1.8(0.8)$ & $3.2(1.1)$ & $3.5(0.8)$ \\
\hline & Hearing with HA & & - & - & $2.4(0.9)$ & $2.6(0.7)$ \\
\hline & Hearing when TV is on & \multirow{12}{*}{$\begin{aligned} 0= & \text { not at all to } 10 \\
& =\text { perfectly }\end{aligned}$} & $7.4(3.1)$ & $8.5(2.0)$ & $5.8(3.5)$ & $6.3(2.0)$ \\
\hline & Hearing both talk and TV & & $7.0(2.8)$ & $7.6(2.4)$ & $5.5(2.9)$ & $5.0(2.5)$ \\
\hline & $\begin{array}{l}\text { Conversation when many other } \\
\text { people are talking }\end{array}$ & & $7.4(2.9)$ & $8.1(2.5)$ & $4.9(2.7)$ & $5.2(2.4)$ \\
\hline & Conversation in group of five & & $7.4(2.7)$ & $7.5(2.6)$ & $4.5(2.8)$ & $4.5(2.3)$ \\
\hline & $\begin{array}{l}\text { Conversation switches from one } \\
\text { person to another }\end{array}$ & & $7.9(2.5)$ & $8.7(1.7)$ & $6.3(2.8)$ & $5.7(2.6)$ \\
\hline & Tell where barking dog is & & $8.5(2.7)$ & $9.2(0.9)$ & $7.0(3.4)$ & $7.2(2.7)$ \\
\hline & Tell how far a bus is & & $7.7(2.8)$ & $8.1(1.6)$ & $6.5(2.8)$ & $6.6(2.6)$ \\
\hline & Tell direction of bus & & $8.4(2.8)$ & $9.0(1.1)$ & $7.0(3.1)$ & $7.6(2.3)$ \\
\hline & Single jumbled sound & & $7.9(2.7)$ & $8.9(1.7)$ & $6.9(2.6)$ & $6.7(2.6)$ \\
\hline & Which instruments are playing & & $8.0(2.5)$ & $8.7(1.4)$ & $7.6(2.5)$ & $7.4(2.2)$ \\
\hline & Clear everyday sounds & & $8.5(2.1)$ & $9.4(0.8)$ & $7.3(2.6)$ & $7.6(1.9)$ \\
\hline & Concentrate when listening & & $7.6(3.0)$ & $8.6(1.9)$ & $6.1(3.5)$ & $5.7(2.6)$ \\
\hline
\end{tabular}

\subsection{Self- reported and clinically measured abilities}

There was an effect of group on general health (rated from $1=$ excellent to $5=$ very poor), such that VI felt significantly healthier compared to $\operatorname{VHI}(F(3,100)=4.17, p=0.05)$. This means that the combination of vision and hearing declines affected the perception of general health more compared to only vision decline $($ Mean $=2.29(0.71)$ compared to $1.66(0.72)$ ). 


\subsubsection{Vision}

The bivariate correlation revealed that the clinical measures of low contrast VA, both with and without glasses, were significantly correlated with subjective reports of eyesight (rated from $1=$ excellent to $5=$ very poor), with and without glasses. However, for the visual fields (number of visible dots) there was no significant correlation. The Pearson $r$-values and $p$-values are presented in Table 3.

Table 3: Correlation between objective and subjective measures of vision with and without glasses respectively. Significant correlations are presented with $r$-value and significance level, $*=p<0.05$ and $* *=p<0.01$.

Subjective eyesight using both eyes is:

Excellent (1) Good (2) Fair (3) Poor (4) Very poor (5)

\begin{tabular}{|l|c|c|}
\hline & \multicolumn{2}{|c|}{ Pearson r-value } \\
\hline & No glasses & Glasses or contact lenses \\
\hline HC & $-0.48^{* *}$ & $-0.47^{* *}$ \\
\hline LC & $-0.46^{* *}$ & $-0.32^{* *}$ \\
\hline VF & -0.03 & 0.05 \\
\hline
\end{tabular}

The objective measures of vision (corrected for participants with VI) were also significantly correlated with several of the subjective measures of eyesight. Reading ordinary print, doing work or hobbies, and reading street signs were strongly associated with the contrast measures, but not with visual field. Going down steps, on the other hand, was significantly correlated with visual field, but not with the contrast measures, see Table 4: Correlation between objective measures of corrected vision and the difficulty in various daily situations

Table 4: Correlation between objective measures of corrected vision and the difficulty in various daily situations for all groups combined. Significant correlations are presented with $r$-value and significance level, $*=p<0.05$ and $* *=p<0.01$.

\begin{tabular}{|c|c|c|c|}
\hline \multicolumn{4}{|c|}{$\begin{array}{l}\text { No difficulty at all (1) a little difficulty (2) moderate difficulty (3) } \\
\text { extreme difficulty (4) }\end{array}$} \\
\hline & \multicolumn{3}{|c|}{ Pearson r-value } \\
\hline & $\mathrm{HC}$ & LC & VF \\
\hline Reading ordinary print & $-0.35 * *$ & $-0.28 * *$ & -0.13 \\
\hline Doing work or hobbies & -0.18 & $-0.23 *$ & 0.03 \\
\hline Finding something on the shelf & 0.05 & -0.05 & -0.05 \\
\hline Reading street signs & $-0.31 * *$ & $-0.24 *$ & -0.13 \\
\hline Going down steps & 0.03 & -0.04 & $-0.41 *$ \\
\hline
\end{tabular}

The distribution of self-reported vision separated for participants with and without vision impairment are shown in Figure 1. VA of at least 1.0 decimal without glasses was defined as no vision impairment. The intention is to illustrate the association between clinically measured eyesight, leading to a categorization of vision impairment or not, and the self-reported visual ability. 


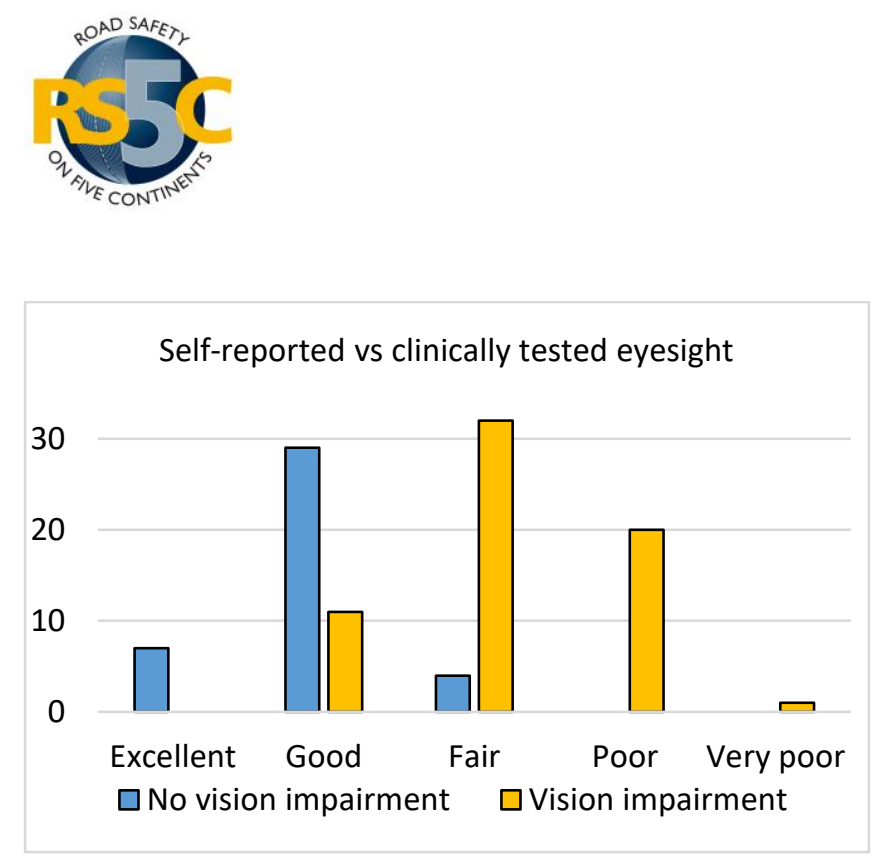

Figure 1: Self-reported eyesight without glasses for participants with and without clinically stated vision impairment, respectively.

\subsubsection{Hearing}

Bivariate correlation was performed also on subjective and objective measures of hearing. Self -reported hearing was significantly moderately correlated both with hearing threshold and with SIN, with and without hearing aids (see Table 5).

Table 5: Correlation between objective and subjective measures of hearing with and without hearing aid respectively. Significant correlations are presented with $r$-value and significance level, $*=p<0.05$ and $* *=p<0.01$.

\begin{tabular}{|l|c|c|}
\hline \multicolumn{2}{|l|}{$\begin{array}{l}\text { Subjective hearing is: } \\
\text { Excellent (1) Good (2) Fair (3) Poor (4) Very poor (5) }\end{array}$} \\
\hline & \multicolumn{2}{|c|}{ Pearson $r$-value } \\
\hline & Without & With HA \\
\hline HA & $0.56^{* *}$ \\
\hline PTA right ear & $0.66^{* *}$ & $0.46^{* *}$ \\
\hline PTA left ear & $0.63^{* *}$ & $-0.48^{* *}$ \\
\hline SIN both ears & $-0.66^{* *}$ & \\
\hline
\end{tabular}

The objective measures of hearing (corrected for participants with HI) were also significantly correlated with all the subjective measures of difficulty in various daily situations. See Table 6.

Table 6: Correlation between objective measures of corrected hearing and the difficulty in various daily situations. Significant correlations are presented with $r$-value and significance level, $*=p<0.05$ and $* *=p<0.01$.

\begin{tabular}{|c|c|c|c|}
\hline \multicolumn{4}{|c|}{ No difficulty at all (1) a little difficulty (2) moderate difficulty (3) extreme difficulty (4) } \\
\hline & \multicolumn{3}{|c|}{ Pearson $r$-value } \\
\hline & HA L & HA R & SIN HA \\
\hline Hearing when TV is on & $-0.50 * *$ & $-0.38 * *$ & $0.49 * *$ \\
\hline Hearing both talk and TV & $-0.46^{* *}$ & $-0.43 * *$ & $0.39 * *$ \\
\hline Conversation with one when others are talking & $-0.44 * *$ & $-0.36 * *$ & $0.44 * *$ \\
\hline Conversation in group of five & $-0.49 * *$ & $-0.45 * *$ & $0.48 * *$ \\
\hline Conversation switches from one to another & $-0.51 * *$ & $-0.41 * *$ & $0.51 * *$ \\
\hline Tell where barking dog is & $-0.48 * *$ & $-0.38 * *$ & $0.51 * *$ \\
\hline Tell how far a bus is & $-0.43 * *$ & $-0.39 * *$ & $0.47 * *$ \\
\hline Tell direction of bus & $-0.35 * *$ & $-0.23 *$ & $0.37 * *$ \\
\hline Single jumbled sound & $-0.33 * *$ & $-0.30 * *$ & $0.36 * *$ \\
\hline Hear which instruments are playing & $-0.20 *$ & -0.19 & $0.20 *$ \\
\hline
\end{tabular}




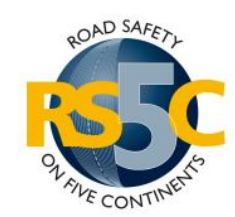

Clear everyday sounds

Concentrate when listening

$-0.42 *$

\begin{tabular}{l|l|l}
$-0.47 * *$ & $-0.45 * *$ & $0.48 * *$
\end{tabular}

The distribution of hearing ratings separated for participants with and without hearing impairment are shown in Figure 2.

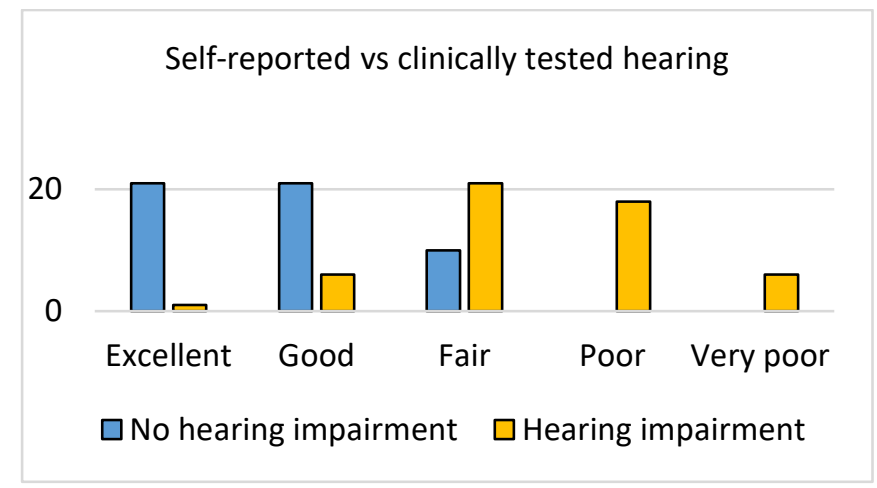

Figure 2: Self-reported hearing without hearing aid for participants with and without clinically stated hearing impairment respectively.

\subsubsection{Tests of visual processing related to driving performance}

Bivariate correlations revealed that cognitive tests were affected by age, such that older age lead to longer times for TMTA $(r=0.35)$ and TMTB $(r=0.33)$, and higher crash risk factor on the UFOV $(r=$ $0.35), p<0.01$. There was a significant correlation between UFOV and both TMTA, $(r=0.32)$ and TMTB $(r=0.58), p<0.01$.

With ANOVA and Post Hoc tests, a significant effect of group was found, such that participants with VHI were slower in finishing the TMTA compared to participants with only VI. $F(3,99)=4.41, p<0.01$, $\operatorname{Mean}(\mathrm{VHI})=56.9(16.4)$ and Mean $(\mathrm{VI})=40.9(13.1)$.

Comparing participants with and without visual impairment revealed a significant effect of vision impairment, such that wearing their optical correction, this group was faster in performing TMTA, $F(1,102)=8.41, p<0.01$, Mean $=42.4$ (13.0) and 51.3 (18.2). Comparing participants with and without hearing impairment revealed no significant effects.

\subsubsection{Self-reported driving performance}

No significant effect was found between self-reported driving performance and visual processing related to driving performance. The joy of driving was significantly correlated with both objective and subjective measures of hearing and vision, such that better ability led to greater pleasure in driving (Table 7). 
Table 7: Driving pleasure was related both to objective and subjective measures of eyesight and to subjective measures of hearing. Here presented with $r$-value and significance level, $*=p<0.05$ and $* *=p<0.01$.

\begin{tabular}{|l|c|}
\hline \multicolumn{2}{|c|}{ Enjoy driving: I don't (1) Yes, a little (2) Yes, somewhat (3) Yes, a lot (4) } \\
\hline HCG & Pearson r-value \\
\hline LCG & $0.34^{* *}$ \\
\hline Eyesight with glasses & $0.32^{* *}$ \\
\hline Difficulty reading ordinary print & $-0.29^{*}$ \\
\hline Difficulty finding something on the shelf & $-0.21^{*}$ \\
\hline Hearing when TV is on & $-0.27^{* *}$ \\
\hline Hearing both talk and TV & $0.29^{* *}$ \\
\hline Tell where barking dog is & $0.21^{*}$ \\
\hline Tell how far a bus is & $0.22^{*}$ \\
\hline Tell direction of bus & $0.20^{*}$ \\
\hline Single jumbled sound & $0.25^{*}$ \\
\hline
\end{tabular}

Perceived driving quality was significantly correlated with both clinically measured vision (at low contrast VA), self-experienced eyesight, and self-experienced hearing, such that better eyesight/hearing led to higher ratings of driving quality (Table 8).

Table 8: Self-perceived driving quality presented with $r$-value and significance level, ${ }^{*}=p<0.05$ and $* *=p<0.01$.

\begin{tabular}{|l|c|}
\hline \multicolumn{2}{|l|}{ Driving quality: Excellent (1) Good (2) Average (3) Fair (4) Poor (5) } \\
\hline & Pearson $r$-value \\
\hline LCG & $-0.26^{*}$ \\
\hline Difficulty finding something on a shelf & $0.30^{* *}$ \\
\hline Hearing without hearing aid & $0.26^{* *}$ \\
\hline Hearing when TV is on & $-0.24^{*}$ \\
\hline Tell how far away a bus is & $-0.28^{* *}$ \\
\hline Tell direction of bus & $-0.28^{* *}$ \\
\hline Single jumbled sound & $-0.21^{*}$ \\
\hline Enjoy driving & $-0.53^{* *}$ \\
\hline
\end{tabular}

There was no significant effect of group (NI, VI, HI, VHI), or when comparing participants with and without hearing impairment (HI+VHI vs NI+VI), or with and without vision impairment (VI+VHI vs $\mathrm{NI}+\mathrm{HI})$ on self-experienced driving quality or the pleasure of driving.

\subsubsection{Level of comfort in various situations}

Correlations were carried out between the level of comfort with driving in various situations and objective hearing and vision measures respectively. For hearing, most significant correlations were found at intersections without traffic lights, in which participants with less hearing ability reported feeling less comfortable. Low contrast VA and visual field significantly affected most situations, such that lower vision ability led to less comfort. All significant effects that were revealed are summarized in Table 9. 
Table 9: Significant effects of clinical (objective) measures on the level of comfort in various situations presented with $r$-value and significance level, $*=p<0.05$ and $* *=p<0.01)$. HA L and HA R are left out, since no significances were found.

\begin{tabular}{|c|c|c|c|c|c|c|c|c|c|}
\hline Situation & NHA R & NHA L & $\begin{array}{l}\text { SIN } \\
\text { NHA }\end{array}$ & $\begin{array}{r}\text { SIN } \\
\text { HA }\end{array}$ & HCNG & LCNG & HCG & LCG & VF \\
\hline Unfamiliar areas & & & & & & $0.20 *$ & & $0.29 *$ & $0.29 *$ \\
\hline $\begin{array}{c}\text { Intersections } \\
\text { without traffic } \\
\text { lights }\end{array}$ & $-0.21 *$ & $-0.19^{*}$ & $0.26 * *$ & & & & & $0.44 * *$ & \\
\hline $\begin{array}{l}\text { Intersections with } \\
\text { traffic lights }\end{array}$ & & & & $0.33 *$ & & & & $0.38 * *$ & $0.28 * *$ \\
\hline High traffic roads & & & & & & & $0.35^{* *}$ & $0.47 * *$ & $0.32 * *$ \\
\hline At night time & & & & & & & & $0.25 *$ & $0.27 * *$ \\
\hline When raining & $-0.21 *$ & & & & & $0.21 *$ & & $0.26 *$ & $0.27 * *$ \\
\hline Alone in the car & & & & $0.35^{*}$ & & & & & $0.24 *$ \\
\hline People in the car & $-0.21 *$ & & & & & & & & 0.25 \\
\hline With radio on & & & & & & & & $0.33 * *$ & \\
\hline Freeway/highway & & & & $0.30 *$ & & & & & $0.23 *$ \\
\hline Peak hour traffic & & & & $0.31 *$ & $0.23 *$ & $0.27 * *$ & $0.26^{*}$ & & \\
\hline Merging & & & & & & & & $0.29 *$ & $0.24 *$ \\
\hline Roundabouts & & & & & & & $0.29 *$ & $0.34 * *$ & \\
\hline
\end{tabular}

ANOVAs revealed no significant differences when dividing into groups (NI, VI, HI, VHI). However, when comparing participants with and without vision impairment (VI+VHI vs NI+HI), the level of comfort was, in some situations, significantly higher in the group without vision impairment. See Table 10 .

Table 10: Significant effects of groups with and without vision impairment. $(0=$ not at all comfortable, $50=$ moderately comfortable, $100=$ completely comfortable). Presented with $F$-value and significance level, ${ }^{*}=p<0.05$.

\begin{tabular}{|l|l|l|l|}
\hline \multicolumn{1}{|c|}{ Situation } & & \multicolumn{2}{c|}{ Mean (SD) } \\
\hline & $\mathrm{F}(1,102)$ & $\mathrm{NI}+\mathrm{HI}$ & $\mathrm{VI}+\mathrm{VHI}$ \\
\hline Unfamiliar areas & $4.41^{*}$ & $78.1(22.1)$ & $69.5(19.1)$ \\
\hline When raining & $5.58^{*}$ & $67.5(24.8)$ & $56.6(21.5)$ \\
\hline In peak hour traffic & $6.90^{*}$ & $83.1(21.5)$ & $70.7(24.6)$ \\
\hline Merging & $5.14^{*}$ & $83.1(22.9)$ & $73.1(21.5)$ \\
\hline Roundabouts & $4.47^{*}$ & $86.3(21.9)$ & $77.3(20.3)$ \\
\hline
\end{tabular}

Similarly, comparison was made between participants with and without hearing impairment (HI+VHI vs NI+VI). The only significant effect was that hearing impairment led to lower feelings of comfort with an emergency vehicle on the road, $\mathrm{F}(1,102)=4.25, \mathrm{p}<0.05$ Mean $(\mathrm{HI}+\mathrm{VHI})=71.6$ (24.3) and $\operatorname{Mean}(\mathrm{NI}+\mathrm{VI})=80.9(20.8)$.

\subsubsection{Use of vision and hearing aids when driving}

For all the participants with vision impairment (VI+VHI), the use of using glasses or contact lenses when driving was high, 95\%-96\% of the time in daylight and night-time driving respectively. There was no effect of dual declines on the extent of using glasses. The subjective comparison of driving with and without vision aid was significantly and positively correlated with; rating of eyesight without glasses or contact lenses, $r=0.27, p<0.05$ wearing glasses for daytime driving, $r=0.70, p<0.01$, and with wearing glasses for night time driving, $r=0.73, p<0.01$. With the high extent of vision aid use, there was no effect of specific traffic situations. 
Participants with hearing impairment (HI+VHI) use their hearing aids on average 57\% (SD=43) of the time when driving. No difference between the ears and no effect of dual impairments was found. The hearing aid use when driving was significantly correlated with subjective comparison of driving with and without hearing aids, $r=0.48, p<0.01$, and with the SINQ, which was the clinical measure of the hearing aid effect used in this study, $r=0.39, p<0.05$. No significant effect of either PTA or subjective rating of hearing, with or without hearing aids, was found on the total usage of HA when driving.

Considering use of hearing aids in specific situations $(1=$ all the time, $2=$ most of the time, $3=$ some of the time, $4=$ rarely or none of the time), there was a significant correlation between comparison of driving with and without hearing aids and the use of hearing aids in each specific situation, $r=0.5-0.6$, $p<0.01$. No significant effect of group (dual declines) or SINQ (hearing aid benefit) on usage of hearing aids in specific situations was found. The mean values were $2.2(\mathrm{SD}=1.3)$ for all situations except for with other people in the car, mean $=1.9(\mathrm{SD}=1.0)$.

\section{DISCUSSION}

The aims of this study were to evaluate self-reported driving abilities and self-reported use of visual and hearing aids for driving, among older adults with varying degrees of HI, VI, and visual processing related to driving performance. The awareness of one's abilities are of great interest. The research questions are discussed under separate corresponding headings. After that, methodological aspects are discussed.

\subsection{How self-reported and clinically measured declines in sensory abilities are associated}

The clinical measures of low contrast VA, both with and without glasses, were significantly correlated with subjective eyesight, with and without glasses. However, for the visual field there was no significant correlation. Also, several of the subjective measures of eyesight in daily situations were significantly correlated with the contrast measures, but not with visual field sensitivity. Possibly people are not as aware of their visual field loss as they are of other declines, given that monocular field loss may be compensated for by normal fields in the other eye and people tend to foveate targets within their environment rather than using their peripheral fields. On the other hand, going down steps was significantly correlated with visual field loss, but not with the low contrast VA measures. This is partly in line with previous research stating that visual field loss and contrast sensitivity increases the risk of falling accidents in older adults (Black, Wood, \& Lovie-Kitchin, 2011; Dhital, Pey., \& Stanford, 2010; E.E. Freeman, Muñoz, Rubin, \& West, 2007).

In general, and in all specific daily situations listed, self-reported hearing was significantly correlated both with hearing threshold and with SIN, with and without hearing aid. This corresponds to previous research examining the validity of subjective hearing ratings (FerriteI, SantanaII, \& MarshalI, 2011).

No significant effect was found between self-reported driving ability and visual processing related to driving performance. Participants with VI, wearing their correction, were faster in completing the TMTA. Possibly people with glasses have better eyesight compared to people who see well enough without glasses. Participants with hearing and vision impairment, compared to those with only vision impairment, needed longer time to complete the TMT. Cognitive skills are affected by hearing impairments (Larsby, Hällgren, Lyxell, \& Arlinger, 2005) and this might be the reason for this result. Also, as could be expected, visual processing performance decreased with age (Edwards et al., 2006). The three tests (TMTA, TMTB, and UFOV) were strongly correlated with each other, which was also expected and in line with previous research (Badenes et al., 2014). Both the joy of driving and the 
perceived driving quality was significantly correlated to hearing and vision, such that better ability led to greater pleasure in driving and higher ratings of driving quality.

\subsection{How self-reported and clinically measured decline is associated with the level of comfort in various situations}

Better clinical measures, of both hearing and vision, were associated with a higher level of comfort in various traffic situations. The situations affected by most measures were intersections without traffic lights, raining, and peak hour traffic. The measures affecting most situations were SIN, LCG, and VF. Less vision at low contrast VA and smaller visual field led to decreased comfort in almost all situations.

The results regarding low contrast VA is in line with previous research, concerning both subjective and objective measures of what. Contrast sensitivity declines in older adults have been associated with driving cessation (E. E. Freeman, Muñoz, Turano, \& West, 2005) or self-regulation (Sandlin, 2014). Impaired driving performance and safety in drivers with cataracts have been shown to be associated with the decrease in contrast sensitivity resulting from cataracts (Owsley, Stalvey, Wells, Sloane, \& McGwin Jr, 2001; Sandlin, 2014; Wood, Chaparro, Carberry, \& Chu, 2010) Some studies have also shown an increase in crash risk with decreased contrast sensitivity (Ball, 2003; Wood, Chaparro, \& Hickson, 2009; Wood \& Troutbeck, 1995). Situations described in the literature as more difficult for persons with decreased visual field are speed adjustment at lane change, (A. Bowers, Peli, Elgin, McGwin, \& Owsley, 2005) , lane and curve positioning, (A. Bowers, \& Peli, E, 2005; A. Bowers et al., 2005; Elgin, 2010; Lockhart, 2009), and reacting to unexpected events in the periphery (Haymes, 2008; Lockhart, 2009).

On group level, participants with VI, compared to those without VI, felt less comfortable in unfamiliar areas, when raining, in peak hour traffic, when merging, and in roundabouts. These situations are visually demanding and sometimes by older adults perceived as certainly difficult and potentially dangerous (Haustein et al., 2013; Jansen et al., 2001). Participants with HI, compared to those without $\mathrm{HI}$, felt less comfortable with an emergency vehicle on the road. Possibly, they notice the emergency vehicle later, due to the hearing loss and feel stressed.

\subsection{How self-reported and clinically measured decline is associated with the use of hearing and vision aids when driving}

Glasses or contact lenses were worn almost all the time when driving, as an effect of the experienced benefit, and there was no effect of dual declines. Hearing aids were used slightly more than half of the time when driving, and this was associated with both objective (SINQ) and subjective measure of assistance of the hearing aid. This research is the first to explore the use of hearing and vision aids when driving and adds interesting insight to how older adults use these aids while driving

\subsection{Method discussion}

A limitation of this study was the relatively small sample sizes in each of the subgroups, given that recruiting participants in each group was difficult. There are very few older adults without vison loss, and even less with only hearing loss and no vision loss. Some people were not aware of their decline and had to be transferred to another group.

In addition, many participants with hearing loss (49\%), did not bring their hearing aid to the testing session. This might be a result of its own since they may not be satisfied with their hearing aid and do not use them very much. 


\section{CONCLUSIONS}

The correlation between subjective and objective measures of both hearing and vision, indicates that participants in this study were aware of their abilities. A better hearing and vision (as clinically measured), were associated with a higher level of comfort in several traffic situations. The results also show that spectacles are used more than hearing aids when driving, in this study $95 \%$ versus $57 \%$ of the time. Both the joy of driving and the perceived driving quality was significantly correlated to hearing and vision, such that better ability led to greater pleasure in driving and higher ratings of driving quality.

\section{REFERENCES}

Arlinger, S. (2007). Nordisk Lärobok i Audiologi. Nordic Textbook of Audiology. Bromma: C-A Tegnér $A B$.

Badenes, D., Garolera, M., Laura Casas, L., Cejudo-Bolivar, J. C., de Francisco, J., Zaragoza, S., . . . Miquel, A. (2014). Driving Competences and Neuropsychological Factors Associated to Driving Counseling in Multiple Sclerosis. Journal of the International Neuropsychological Society, 20, 555-565.

Ball, K., \& Owsley, C. (2003). Driving Competence: It's Not a Matter of Age. . Journal of the American Geriatrics Society, 51(1), 1499-1150. doi:10.1046/j.1532-5415.2003.51487.x

Black, A. A., Wood, J. M., \& Lovie-Kitchin, J. E. (2011). Inferior field loss increases rate of falls in older adults with glaucoma. Optometry and Vision Science, 88(11), 1275-1282.

Bohensky, M., Charlton, J., Odell, M., \& Keefe, J. (2008). Implications of vision testing for older driver licensing. Traffic Injury Prevention, 9(4), 304-313. doi:10.1080/15389580801895277

Bowers, A., \& Peli, E. (2005). Assessing driving performance with moderate visual field loss. Paper presented at the Third International Driving Symposium on Human Factors in Driver Assessment, Training and Vehicle Design, Maine, USA.

Bowers, A., Peli, E., Elgin, J., McGwin, G., \& Owsley, C. (2005). On-Road Driving with Moderate Visual Field Loss. Optometry and Vision Science, 82(8), 657-667.

Cohen, J. (1988). Statistical power analysis for the behavioural sciences Hillsdale, NJ: Lawrence Erlbaum Associates.

Cox, R. M., \& Alexander, G. C. (1999). Measuring satisfaction with amplification in daily life: the SADL scale. Ear and Hearing, 20(4), 306-320. 
Crabb, D. P., Viswanathan, A.C. (2004). Integrated visual fields: a new approach to measuring the binocular field of view and visual disability. Graefe's Archive for Clinical and Experimental Ophthalmology, 243(3), 210-216.

Cushman, L. A. (1996). Cognitive capacity and concurrent driving performance in older drivers. IATSS Res, 20, 38-45.

Dhital, A., Pey., T., \& Stanford, M. R. (2010). Visual loss and falls: a review. Eye, 24, 1437-1446

Edwards, J. D., Ross, L. A., Wadley, V. G., Clay, O. J., Crowe, M., Roenker, D. L., \& Ball, K. K. (2006). The useful field of view test: Normative data for older adults. Archives of Clinical Neuropsychology, 21(4), 275-286.

Elgin, J., McGwin, G., Wood, J. M., Vaphiades, M. S., Braswell, R. A., DeCarlo, D. K., Owsley, C. (2010). Evaluation of On-Road Driving in Persons with Hemianopia and Quadrantanopia. American Journal of Occupational Therapy, 64(2), 268-278.

Ellaway, A., Macintyre, S., Hiscock, R., \& Kearns, A. (2003). In the driving seat: psychosocial benefits from private motor vehicle transport compared to public transport. Transportation Research Part F: Traffic Psychology and Behaviour, 6, 217-231.

Ferritel, S., Santanall, V. S., \& Marshall, S. W. (2011). Validity of self-reported hearing loss in adults: performance of three single questions. Rev Saúde Pública, 45(5), 824-830.

Freeman, E. E., Muñoz, B., Rubin, G., \& West, S. K. (2007). Visual Field Loss Increases the Risk of Falls in Older Adults: The Salisbury Eye Evaluation. Investigative Ophthalmology \& Visual Science, 48(10).

Freeman, E. E., Muñoz, B., Turano, K. A., \& West, S. H. (2005). Measures of Visual Function and Time to Driving Cessation in Older Adults: Associations Between Visual, Hearing, and Dual Sensory American Academy of Optometry, 82(8), 765-773.

Groeger, J. A. (2000). Understanding driving: applying cognitive psychology to a complex everyday task. London: Routledge.

Haustein, S., Sirén, A., Franke E., Pokrieke, E., Alauzet, A., Marin-Lamellet, C., . . O'Neill, D. (2013). Demographic change and transport. Retrieved from Final report of WP1:Consol. :

Haymes, S. A., LeBlanc, R. P., Nicolela, M. T., Chiasson, L. A., \& Chauhan, B. C. (2008). Glaucoma and on-road driving performance. Opthalmology \& Visual Science, 49(7), 3035-3041.

doi:10.1167/iovs.06-0886 
Hoffman, L., McDowd, J., Atchley, P., \& Dubinsky, R. (2015). The Role of Visual Attention in Predicting Driving Impairment in Older Adults. Psychology and Aging, 20(4), 610-622.

Jansen, E., Holte, H., Jung, C., Kahmann, V., Moritz, K., Rietz, C., ... Weidemann, C. (2001). Ältere Menschen im künftigen Sicherheitssystem Straße/Fahrzeug/Mensch. [Senior citizens in the future safety system: street/vehicle/person] Bremerhaven: Wirtschaftsverlag NW.

Johnson, C. A., \& Wilkinson, M. E. (2010). Vision and driving: The United States. Journal of NeuroOphthalmology, 30, 170-176. doi:10.1097/WNO.0b013e3181df30d4

Larsby, B., Hällgren, M., Lyxell, B., \& Arlinger, S. (2005). Cognitive performance and perceived effort in speech processing tasks: Effects of different noise backgrounds in normal-hearing and hearing-impaired subjects. International Journal of Audiology, 44, 131-143.

Likert, R. (1932). A technique for the measurement of attitudes. Archives of Psychology, 22(140), 155.

Lockhart, J., Boyle, L. N., \& Wilkinson, M (2009). Driving with visual field loss: An exploratory simulation study. NHTSA (Report No: DOT HS 811 062)

Magnusson, L., Karlsson, M., \& Leijon, A. (2001). Predicted and measured speech recognition performance in noise with linear amplification. Ear and Hearing, 22(1).

Mangione, C. M., Lee, P. P., Gutierrez, P. R., Spritzer, K., Berry, S., \& Hays, R. D. (2001). Development of the 25-item National Eye Institute Visual Function Questionnaire (VFQ-25). Archives of Ophthalmology, 119, 1050-1058.

Myers, R., Ball, K. K., Kalina, T. D., Roth, D. L., \& Goode, K. T. (2000). Relation of Useful field of view and other screening tests to on-road driving performance. Perceptual and motor skills, 91, 279-290.

Owsley, C., Ball, K., McGwin Jr, G., Sloane, M. E., Roenker, D. L., White, M. F., \& Overley, E. T. (1998). Visual processing impairment and risk of motor vehicle crash among older adults. JAMA, 279, 1083-1088.

Owsley, C., Stalvey, B., Wells, T., Sloane, M., \& McGwin Jr, G. (2001). Visual risk factors for crash involvement in older drivers with cataract. Archives Ophthalmology, 119, 881-887. doi:10.1001/archopht.119.6.881 
Rapoport, M. J., Naglie, K., Weegar, A., Myers, D., Cameron, A., Crizzle, N., . . Marshall. (2013). The relationship between cognitive performance, perceptions of driving comfort and abilities, and self-reported driving restrictions among healthy older drivers. Accident Analysis \& Prevention, 61, 288-295.

Reger, M. A., Welsh, R. K., Watson, G. S., Cholerton, B., Baker, L. D., \& Craft, S. (2004). The relationship between neuropsychological functioning and driving ability in dementia: A metaanalysis. Neuropsychology, 18, 85-93. doi:10.1037/0894-4105.18.1.85

Reitan, R. (1986). Trail making test. Manual for administration and scoring. Tuscon, AZ: Neuropsychological Laboratory.

Sandlin, D., McGwin, G., \& Owsley, C. (2014). Association Between Vision Impairment and Driving Exposure in Older Adults Aged 70 Years and Over: A Population-Based Examination. Acta Ophthalmologica Scandinavica, 92(3), 207-212. doi:10.1111/aos.12050

Thorslund, B. (2014). Effects of hearing loss on traffic safety and mobility. (Doctoral dissertation), Linköping University Electronic Press, Linköping.

Thorslund, B., \& Strand, N. (2016). Vision measurability and its impact on safe driving - a literature review. Scandinacian Journal of Vision Science, 9(1).

Transportstyrelsen. (2012). De medicinska kraven i trafiken: Mecical requirements in traffic. Retrieved from https://www.transportstyrelsen.se/globalassets/global/publikationer/vag/trafikmedicin/pro dukter/de medicinska kraven low.pdf

Wood, J. M., Chaparro, A., Carberry, T., \& Chu, S. (2010). Effect of simulated visual impairment on nighttime driving performance. Optometry and Vision Science,, 87(6), 379-386.

Wood, J. M., Chaparro, A., \& Hickson, L. (2009). Interaction between visual status, driver age and distracters on daytime driving performance. Vision Research, 49, 2225-2231. doi:10.1016/j.visres.2009.06.017

Wood, J. M., \& Troutbeck, R. (1995). Elderly drivers and simulated visual impairment. Optometry and Vision Science, 72(124-155).

Zhang, J., Tyler, R., Ji, H., Dunn, C., Wang, N., Hansen, M., \& Gantz, B. (2015). Speech, Spatial and Qualities of Hearing Scale (SSQ) and Spatial Hearing Questionnaire (SHQ) Changes Over Time in Adults With Simultaneous Cochlear Implants. American Journal of Audiology, 24, 384-397. 
9. APPENDIX DRIVING, VISION AND HEARING QUESTIONNAIRE Section 1: First, we'd like to ask a few questions about you:

What is your date of birth?

What is your gender? $\square$ Male $\square$ Female

In general, would you say your health is:
$\square$ Excellent
$\square$ Very good
$\square$ Good
$\square$ Fair
Poor

\section{Section 2: This section asks about your vision.}

At the present time, would you say your eyesight using both eyes (without glasses or contact lenses) is:
$\square$ Excellent
$\square$ Good
$\square$ Fair
$\square$ Poor
Very poor

At the present time, would you say your eyesight using both eyes (with glasses or contact lenses, if you wear them) is:
Excellent
Good
$\square$ Fair
$\square$ Poor
Very poor

The following questions are about how much difficulty, if any, you have doing certain activities wearing your glasses or contact lenses if you use them for that activity.

How much difficulty do you have reading ordinary print in newspapers (wearing your glasses if you use them)? Would you say you have:

\begin{tabular}{|c|c|c|c|c|c|}
\hline $\begin{array}{l}\square \text { No } \\
\text { difficulty } \\
\text { at all }\end{array}$ & $\begin{array}{l}\square \text { A little } \\
\text { difficulty }\end{array}$ & $\begin{array}{l}\square \text { Moderate } \\
\text { difficulty }\end{array}$ & $\begin{array}{l}\square \text { Extreme } \\
\text { difficulty }\end{array}$ & $\begin{array}{l}\square \text { Stopped } \\
\text { doing this } \\
\text { because of } \\
\text { your eyesight }\end{array}$ & $\begin{array}{l}\square \text { Stopped doing this } \\
\text { for other reasons or } \\
\text { not interested in doing } \\
\text { this }\end{array}$ \\
\hline
\end{tabular}

How much difficulty do you have doing work or hobbies that require you to see well up close, such as cooking, sewing, fixing things around the house, or using hand tools (wearing your glasses if you use them)? Would you say:

\begin{tabular}{|c|c|c|c|c|c|}
\hline $\begin{array}{l}\square \text { No } \\
\text { difficulty } \\
\text { at all }\end{array}$ & $\begin{array}{l}\square \text { A little } \\
\text { difficulty }\end{array}$ & $\begin{array}{l}\square \text { Moderate } \\
\text { difficulty }\end{array}$ & $\begin{array}{l}\square \text { Extreme } \\
\text { difficulty }\end{array}$ & $\begin{array}{l}\square \text { Stopped } \\
\text { doing this } \\
\text { because of } \\
\text { your eyesight }\end{array}$ & $\begin{array}{l}\square \text { Stopped doing this } \\
\text { for other reasons or } \\
\text { not interested in doing } \\
\text { this }\end{array}$ \\
\hline
\end{tabular}


Because of your eyesight, how much difficulty do you have finding something on a crowded shelf (wearing your glasses if you use them)?

$\begin{array}{llllll}\square \text { No } & \square \text { Alittle } & \square \text { Moderate } & \square \text { Extreme } & \square \text { Stopped } & \square \text { Stopped doing this } \\ \text { difficulty } & \text { difficulty } & \text { difficulty } & \text { difficulty } & \begin{array}{l}\text { doing this } \\ \text { because of }\end{array} & \text { for other reasons or } \\ \text { at all } & & & \text { nour interested in doing } \\ & & & & \text { yought } & \text { this }\end{array}$

How much difficulty do you have reading street signs or the names of stores (wearing your glasses if you use them)?

$\begin{array}{lllll}\square \text { No } & \square \text { A little } & \square \text { Moderate } & \square \text { Extreme } \\ \text { difficulty } & \text { difficulty } & \text { difficulty } & \begin{array}{l}\square \text { Stopped } \\ \text { doing this } \\ \text { because of }\end{array} & \begin{array}{l}\square \text { Stopped doing this } \\ \text { for other reasons or } \\ \text { at all }\end{array} \\ & & \text { your eyesight } & \text { this }\end{array}$

Because of your eyesight, how much difficulty do you have going down steps, stairs, or curbs in dim light or at night (wearing your glasses if you use them)?

\begin{tabular}{|c|c|c|c|c|c|}
\hline $\begin{array}{l}\square \text { No } \\
\text { difficulty } \\
\text { at all }\end{array}$ & $\begin{array}{l}\square \text { A little } \\
\text { difficulty }\end{array}$ & $\begin{array}{l}\square \text { Moderate } \\
\text { difficulty }\end{array}$ & $\begin{array}{l}\square \text { Extreme } \\
\text { difficulty }\end{array}$ & $\begin{array}{l}\square \text { Stopped } \\
\text { doing this } \\
\text { because of } \\
\text { your eyesight }\end{array}$ & $\begin{array}{l}\square \text { Stopped doing this } \\
\text { for other reasons or } \\
\text { not interested in doing } \\
\text { this }\end{array}$ \\
\hline
\end{tabular}

\section{Section 3: This section asks about your hearing. Please choose the response that best describes your situation.}

At the present time, would you say your hearing (without hearing aid/s) is:
$\square$ Excellent
$\square$ Good
$\square$ Fair
$\square$ Poor
Very poor

At the present time, would you say your hearing (with hearing aid/s, if you wear them) is:
$\square$ Excellent
$\square$ Good
$\square$ Fair
$\square$ Poor
$\square$ Very poor

For the following questions please put a cross anywhere on a scale shown against each question that best describes your situation and answer as if you were wearing your hearing aids (if any).

You are talking with one other person and there is a TV on in the same room. Without turning the TV down, can you follow what the person you are talking to says?

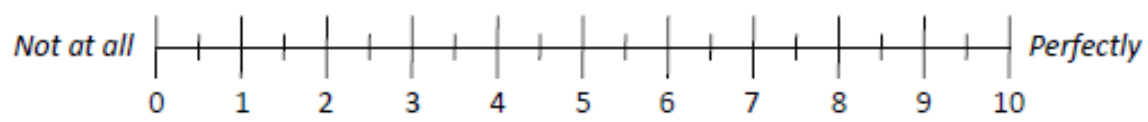

Not applicable 
You are listening to someone talking to you, while at the same time trying to follow the news on TV. Can you follow what both people are saying?

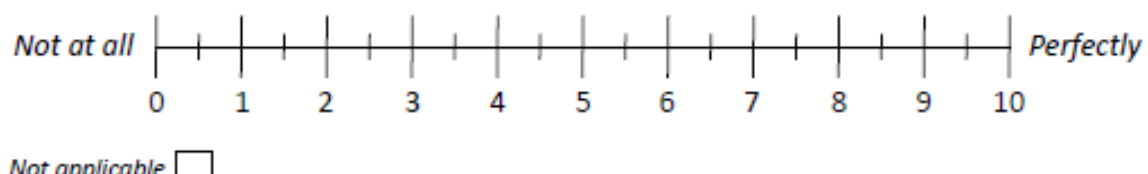

You are in conversation with one person in a room where there are many other people talking. Can you follow what the person you are talking to is saying?

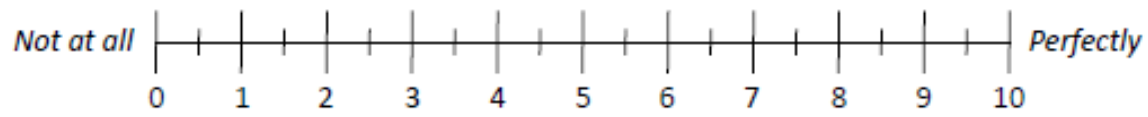

Not applicable

You are in a group of about five people in a busy restaurant. You can see everyone else in the group. Can you follow the conversation?

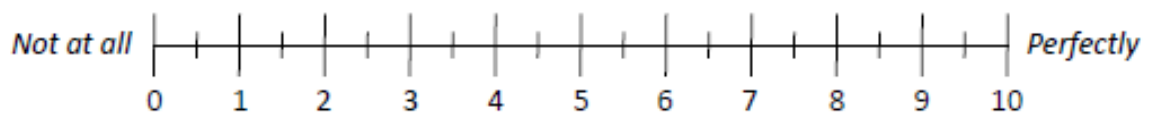

Not applicable

You are with a group and the conversation switches from one person to another. Can you easily follow the conversation without missing the start of what each new speaker is saying

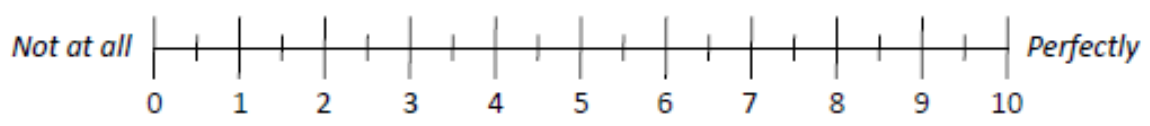

Not applicable

You are outside. A dog barks loudly. Can you tell immediately where it is without having a look?

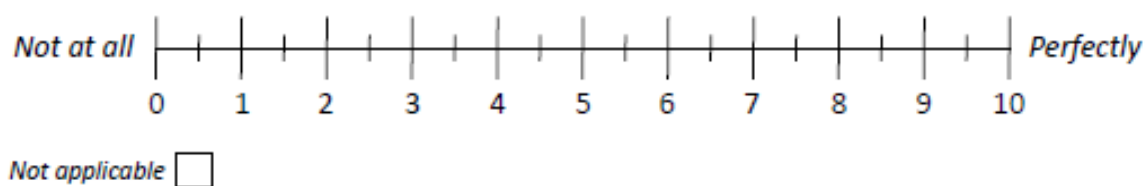

Can you tell how far away a bus or a truck is from the sound? 


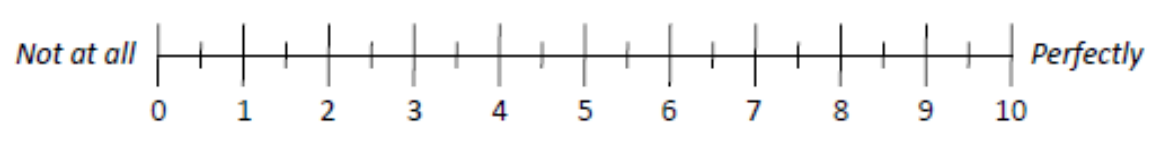

Not applicable

Can you tell from the sound whether a bus or truck is coming towards you or going away?

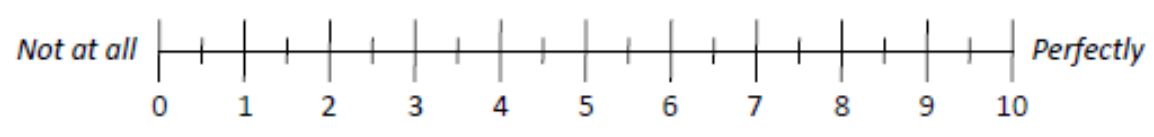

Not applicable

When you hear more than one sound at the time, do you have the impression that it seems like a single jumbled sound?

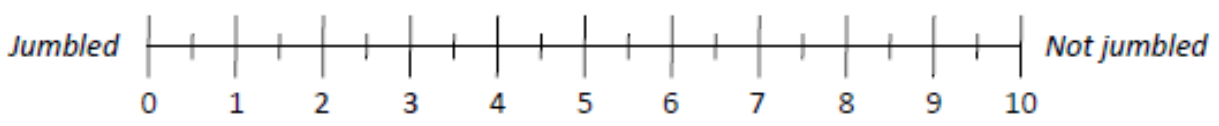

Not applicable

When you listen to music can you make out which instruments are playing?

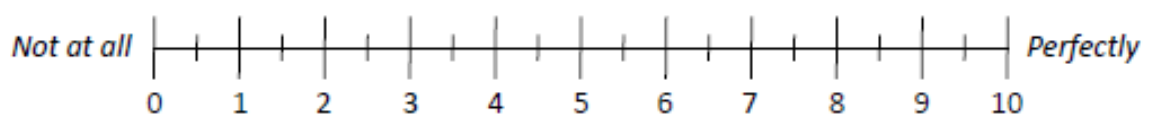

Not applicable

Do everyday sounds that you can hear easily seem clear to you (not blurred)?

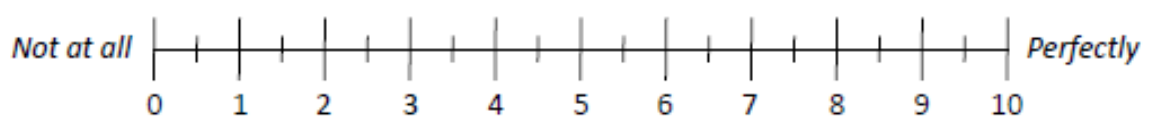

Not applicable

Do you have to concentrate very much when listening to someone or something?

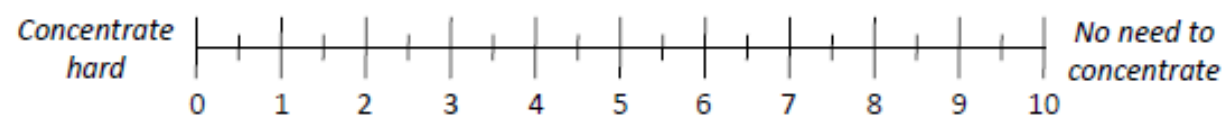

Not applicable 
Section 4: This section asks about your driving habits. Please choose the response that best describes your situation.

Which year did you get your driving license? 19

In a typical week, how many kilometres do you normally drive? $\mathrm{km}$

In a typical week, how many days per week do you normally drive? days

Would you say you enjoy driving a car?
$\square$ No, I don't
Yes, a little
Yes, somewhat
Yes, a lot

How would you rate the quality of your driving, would you say it is?
$\square$ Excellent
$\square$ Good
Average
$\square$ Fair
Poor

Please rate your level of comfort when driving in each of the following situations by choosing a number from the scale below.

If you do not normally drive in the situation, imagine how comfortable you would be if you absolutely had to go somewhere and found yourself in the situation.

In your ratings, consider confidence in your own abilities and driving skills, as well as the situation itself (including other drivers). Assume normal traffic flow unless otherwise specified.

\begin{tabular}{|l|c|c|c|c|c|}
\cline { 2 - 5 } \multicolumn{1}{l|}{} & $\begin{array}{c}\text { Not at all } \\
\text { comfortable } \\
0 \%\end{array}$ & $25 \%$ & $\begin{array}{c}\text { Moderately } \\
\text { comfortable } \\
50 \%\end{array}$ & $\begin{array}{c}\text { Completely } \\
\text { comfortable } \\
100 \%\end{array}$ \\
\hline In familiar areas & $\square$ & $\square$ & $\square$ & $\square$ & $\square$ \\
\hline In unfamiliar areas & $\square$ & $\square$ & $\square$ & $\square$ & $\square$ \\
\hline $\begin{array}{l}\text { At intersections without } \\
\text { traffic lights }\end{array}$ & $\square$ & $\square$ & $\square$ & $\square$ & $\square$ \\
\hline $\begin{array}{l}\text { At intersections with traffic } \\
\text { lights }\end{array}$ & $\square$ & $\square$ & $\square$ & $\square$ & $\square$ \\
\hline On high traffic, busy roads & $\square$ & $\square$ & $\square$ & $\square$ & $\square$ \\
\hline On low traffic, quiet roads & $\square$ & $\square$ & $\square$ & $\square$ & $\square$ \\
\hline Turning right across traffic & $\square$ & $\square$ & $\square$ & $\square$ & $\square$ \\
\hline At night-time & $\square$ & $\square$ & $\square$ & $\square$ & $\square$ \\
\hline When raining & $\square$ & $\square$ & $\square$ & $\square$ & $\square$ \\
\hline When alone in the car & $\square$ & $\square$ & $\square$ & $\square$ & $\square$ \\
\hline
\end{tabular}




\begin{tabular}{|l|c|c|c|c|c|}
\hline $\begin{array}{l}\text { With other people in the } \\
\text { car }\end{array}$ & $\square$ & $\square$ & $\square$ & $\square$ & $\square$ \\
\hline $\begin{array}{l}\text { With an emergency vehicle } \\
\text { on the road }\end{array}$ & $\square$ & $\square$ & $\square$ & $\square$ & $\square$ \\
\hline $\begin{array}{l}\text { With the radio on in the } \\
\text { car }\end{array}$ & $\square$ & $\square$ & $\square$ & $\square$ & $\square$ \\
\hline $\begin{array}{l}\text { On a freeway or high speed } \\
\text { highway }\end{array}$ & $\square$ & $\square$ & $\square$ & $\square$ & $\square$ \\
\hline In peak hour traffic & $\square$ & $\square$ & $\square$ & $\square$ & $\square$ \\
\hline Merging with other traffic & $\square$ & $\square$ & $\square$ & $\square$ & $\square$ \\
\hline On roundabouts & $\square$ & $\square$ & $\square$ & $\square$ & $\square$ \\
\hline
\end{tabular}

Is there something that you try to do in general to improve your safety when driving? Please describe:

Section 5: This section asks about wearing glasses when driving. Please choose the response that best describes your situation.

Do you have any glasses that correct your vision for distance?

$\square$ Yes

$\square$ No (If No, please skip to the Section 6)

What type of glasses do you currently have (if you use several glasses, select the type you would use most often when driving)?
Distance $\square$ Bifocals
$\square$ Trifocals
$\square$ Progressives
Other:

focus only

Approximately how long has it been since you had the lenses in your driving glasses changed? (month/year)

How would you rate your eyesight with your glasses when driving?
Excellent
Good
Average
Fair
Poor

How would you rate your eyesight without your glasses when driving?
$\square$ Excellent
$\square$ Good
Average
Fair
Poor

If you compare driving with and without your glasses, would you say it is:
$\square \quad$ A lot worse
$\square$ A little worse
$\square$ The same with
A little better with glasses with glasses glasses with glasses
A lot better with glasses

To what extent (percent) do you wear your glasses for day-time driving? $\%$ 
To what extent (percent) do you wear your glasses for night-time driving? $\%$

How often would you wear your glasses in the following situations (give an estimate even if you don't drive in these situations):

\begin{tabular}{|l|c|c|c|c|}
\cline { 2 - 5 } & $\begin{array}{c}\text { All of the } \\
\text { time }\end{array}$ & $\begin{array}{c}\text { Most of the } \\
\text { time }\end{array}$ & $\begin{array}{c}\text { Some of the } \\
\text { time }\end{array}$ & $\begin{array}{c}\text { Rarely, or } \\
\text { none of the } \\
\text { time }\end{array}$ \\
\hline In familiar areas & $\square$ & $\square$ & $\square$ & $\square$ \\
\hline In unfamiliar areas & $\square$ & $\square$ & $\square$ & $\square$ \\
\hline At intersections without traffic lights & $\square$ & $\square$ & $\square$ & $\square$ \\
\hline At intersections with traffic lights & $\square$ & $\square$ & $\square$ & $\square$ \\
\hline On high traffic, busy roads & $\square$ & $\square$ & $\square$ & $\square$ \\
\hline On low traffic, quiet roads & $\square$ & $\square$ & $\square$ & $\square$ \\
\hline Turning right across traffic & $\square$ & $\square$ & $\square$ & $\square$ \\
\hline At night-time & $\square$ & $\square$ & $\square$ & $\square$ \\
\hline When raining & $\square$ & $\square$ & $\square$ & $\square$ \\
\hline When alone in the car & $\square$ & $\square$ & $\square$ & $\square$ \\
\hline With other people in the car & $\square$ & $\square$ & $\square$ & $\square$ \\
\hline $\begin{array}{l}\text { With an emergency vehicle on the } \\
\text { road }\end{array}$ & $\square$ & $\square$ & $\square$ & $\square$ \\
\hline With the radio on in the car & $\square$ & $\square$ & $\square$ & $\square$ \\
\hline On a freeway or high speed highway & $\square$ & $\square$ & $\square$ & $\square$ \\
\hline In peak hour traffic & $\square$ & $\square$ & $\square$ & $\square$ \\
\hline Merging with other traffic & $\square$ & $\square$ & $\square$ & $\square$ \\
\hline On roundabouts & $\square$ & $\square$ & $\square$ \\
\hline
\end{tabular}

If you don't wear your glasses all the time when driving, please describe why: 
Section 6: This section asks about wearing hearing aids when driving. Please choose the response that best describes your situation.

Do you own hearing aids?

$\square$ Yes - for both ears

Yes - for one ear only

No (If No, thank you for your participation)

Approximately how long has it been since you received your most recent hearing aids? (month/year)

In everyday life, do you usually wear both, one, or neither of your hearing aids?

What type of hearing aids do you have?

\begin{tabular}{|lllll}
\hline Right Ear: & $\square$ In the ear & $\square$ Behind the ear & $\square$ Other & $\square$ None \\
\hline Left Ear: & $\square$ In the ear & $\square$ Behind the ear & $\square$ Other & $\square$ None \\
\hline
\end{tabular}

Think about how much you used your present hearing aids over the past two weeks. On an average day how many hours do you use the hearing aids?

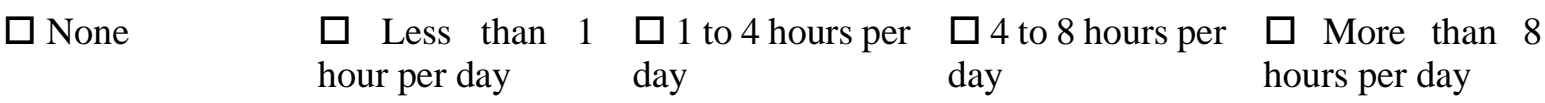

To what extent (percent) do you wear your hearing aids for driving?

In both ears $\%$

| In right ear $\%$

| In left ear $\%$

If you compare driving with and without hearing aids, would you say it is:
$\square$ A lot worse
$\square$ A little worse
$\square$ The same with with hearing aids with hearing aids hearing aids
A little better with hearing aids
A lot better with hearing aids

Do you ever change the settings of your hearing aid/s when driving?

$\square$ No

Yes, please specify what changes you make: 
How often would you wear your hearing aid/s in the following situations (give an estimate even if you don't drive in these situations)

\begin{tabular}{|l|c|c|c|c|}
\cline { 2 - 5 } \multicolumn{1}{c|}{} & $\begin{array}{c}\text { All of the } \\
\text { time }\end{array}$ & $\begin{array}{c}\text { Most of the } \\
\text { time }\end{array}$ & $\begin{array}{c}\text { Some of the } \\
\text { time }\end{array}$ & $\begin{array}{c}\text { Rarely, or } \\
\text { none of the } \\
\text { time }\end{array}$ \\
\hline In familiar areas & $\square$ & $\square$ & $\square$ & $\square$ \\
\hline In unfamiliar areas & $\square$ & $\square$ & $\square$ & $\square$ \\
\hline At intersections without traffic lights & $\square$ & $\square$ & $\square$ & $\square$ \\
\hline At intersections with traffic lights & $\square$ & $\square$ & $\square$ & $\square$ \\
\hline On high traffic, busy roads & $\square$ & $\square$ & $\square$ & $\square$ \\
\hline On low traffic, quiet roads & $\square$ & $\square$ & $\square$ & $\square$ \\
\hline Turning right across traffic & $\square$ & $\square$ & $\square$ & $\square$ \\
\hline At night-time & $\square$ & $\square$ & $\square$ & $\square$ \\
\hline When raining & $\square$ & $\square$ & $\square$ & $\square$ \\
\hline When alone in the car & $\square$ & $\square$ & $\square$ & $\square$ \\
\hline With other people in the car & $\square$ & $\square$ & $\square$ & $\square$ \\
\hline With an emergency vehicle on the & $\square$ & $\square$ & $\square$ & $\square$ \\
\hline road & $\square$ & $\square$ & $\square$ & $\square$ \\
\hline With the radio on in the car & $\square$ & $\square$ & $\square$ & $\square$ \\
\hline On a freeway or high speed highway & $\square$ & $\square$ & $\square$ & $\square$ \\
\hline In peak hour traffic & $\square$ & $\square$ & $\square$ \\
\hline Merging with other traffic & $\square$ & $\square$ & $\square$ \\
\hline On roundabouts & $\square$ & $\square$ & $\square$ & $\square$ \\
\hline
\end{tabular}

If you don't wear your hearing aid/s all the time when driving, please describe why: 